\title{
Virtual Reality: General Issues of Legal Regulation
}

\author{
Roman Dremliuga ${ }^{1}$, Olga Dremliuga ${ }^{1} \&$ Andrei Iakovenko ${ }^{1}$ \\ ${ }^{1}$ School of Law, Far Eastern Federal University, Vladivostok, Russia \\ Correspondence: Roman Dremliuga, School of Law, Far Eastern Federal University, Vladivostok, Russia. Tel: \\ 8-914-707-1474. E-mail: dreamluck@yandex.ru
}

Received: November 8, 2019

Accepted: December 30, 2019 Online Published: February 19, 2020

doi:10.5539/jpl.v13n1p75

URL: https://doi.org/10.5539/jpl.v13n1p75

\begin{abstract}
The article focuses on the general issues of legal regulation of relations that emerge in the field of application of VR technologies and presents issues associated with the regulation of development of such technologies. It looks at the features of this technology that create challenges for the development of a system of legal regulation of its application. The article also gives a perspective at major factors that make application of the existing law difficult and offers analysis of the emerging issues of its regulation. The author arrives at a conclusion that this technology is fundamentally different from the other existing technologies as it combines the properties of both physical reality and cyberspace. Among the challenges of the legal regulation of VR are a high realism, complete immersion user experience, and low cyber protection of both hardware and software components. The author evaluates several regulatory approaches, which could be used in the case of virtual reality and finds that all of them have major deficiencies. Contemporary research findings in secure application of VR in the fields of teaching and entertainment get rapidly outdated as they cannot catch up with the technology development, therefore they can only serve as a ground for the development of a system of VR regulation with consideration of this factor.
\end{abstract}

Keywords: virtual reality, VR, information technologies, issues of regulation, cyber law, virtual reality security, cyber security, IT law, immersive virtual environments

\section{Introduction}

Virtual reality (VR) is one of the technologies that will soon transform our world. ${ }^{1}$ However, other breakthrough technologies such as artificial intelligence or the internet of things attract more attention of both the general public and the government. Nonetheless, a wide application of VR will transform our world beyond recognition. This technology will allow to create new worlds that people would prefer over reality.

As of now, VR technologies are being actively used in many industries. Especially often they are used in the entrainment industry and video games. ${ }^{2}$ There is also a proven efficiency of virtual reality in teaching and modeling of the learning situations (Ahn, 2016). There are cases of application of these technologies in medicine, rehabilitation of felons, video conferencing, etc.

Virtual reality technology is based on a variety of hardware and software tools, which help user(s) imitate a real or fictional world by stimulating their senses such as vision, hearing, touch, smell, sense of balance, etc. In turn, virtual reality is a world or an interaction environment, imitated by such a technology. The most common VR device is the virtual reality helmet, which could be used for imitation of the outside world through video and audio channels. For instance, if somebody uses a VR helmet, a gaming wheel, and a racing track simulator, their head turns and other body movements will be accompanied by changes in the visual environment of the helmet while the rotation of the gaming wheel will imitate the direction of motion of the racing car. Unlike traditional video games where users control body motion by pressing their console keys, VR ensures higher degree of realism and immersion.

Retail statistics demonstrates that the numbers of VR gadget (mostly helmets) sold in the world are rapidly increasing and based on some assessments between 2018 and 2022 they would grow sevenfold reaching 70

\footnotetext{
${ }^{1}$ Market of Virtual and Augmented Reality: Opportunities for Start-up Companies from the Perspective of an Investor. Published by the Internet Initiatives Development Fund (in Russian) https://habr.com/ru/company/friifond/blog/322230/

2 Global virtual reality video gaming sales $2015-2020$

https://www.statista.com/statistics/499714/global-virtual-reality-gaming-sales-revenue/
} 
million units. Among the countries with the largest investments in VR and AR (Augmented Reality) are the United States (USD 6,6 billion) and China (USD 6,0 billion). Some experts assess the growth of this market by the figure of $70 \%$ per annum. ${ }^{3}$

\section{Key Features of VR}

It might seem that virtual reality is yet another new technology, which requires development of new technical standards rather than new legal approaches to regulate it but there is a number of reasons why this is not so. In my opinion due to its features, this technology requires fundamentally new legal solutions.

\subsection{High Degree of Realism}

First feature of VR is its ability to offer a high degree of realism, which translates into reactions of both user's brain and body in the fictional worlds. In VR users can be scared to death, suffer mental and phycological disorders, and even have their consciousness and consumer choices more effectively manipulated among multiple other things (Park, 2018). The fact that virtual reality can help users cope with the stress also means that it can used to induce stressful situations.

Research findings of multiple experiments demonstrate that within several minutes of exposure to VR, human brain and body start reacting to things that happen in there in the same ways they would in the real world. VR users get a fear of virtual heights (Clark, 2013), get scared to death of virtual spiders (Tardif, 2019), and experience worries during social interactions (Diemer, 2015). Multiple research publications demonstrate that virtual reality is a great way of manipulation of psycho-emotional state of users (Abdullah, 2018), especially when gamification is applied (Hvass, 2018).

It should be emphasized that VR technologies become more and more realistic as each year passes by. 3D space in the VR helmets gets better designed and more clearly outlined while VR feedback suits become more sophisticated as they imitate the body touch. ${ }^{4}$ Greater realism can make VR more attractive to a wider audience literally in any industry. Most recent technology developments can even imitate a realistic sexual intercourse with a mimicking of physical contact for users who are located in different parts of the world. Some researchers say that thanks to a high degree of realism and safety more and more people would start to prefer virtual reality to the real world as a place of their pastime (Hvass, 2018).

\subsection{Complete Immersion Experience}

The second feature of VR is that it offers users a complete immersion experience. Unlike augmented reality, traditional video games, and applications displayed on the computer screens where users look at the real world and the things that happen around it, virtual reality helmets fully focus hearing and sight of the users on the imitated reality. If the users use the feedback suits, ${ }^{5}$ then they can cut off yet another channel of incoming impulses.

In this fashion users can fully immerse into a fictional world where they think, sense the time (Bansal, 2019) and their bodies (Thaler, 2019), and where they move based on the features of the fictional world (Brungart, 2019). This is now being actively used in medical treatment where patients can be immersed into a new world where they can get distracted from their pains and fears, and other unpleasant feelings (Yuan, 2018). Some countries seriously practice VR to lower aggression and eliminate other deviations to help users. ${ }^{6}$ At the same time, it should be understood that for many people VR can become a new addiction or a habit that would serve as a medium of escaping reality.

\subsection{Low Security of Virtual Reality Gadgets and Software}

The third feature of VR that should also be remembered is the low security of virtual reality gadgets and software in the context of their cyber vulnerability. According to some scholars' research, most of the popular gadgets have a low or a medium level protection against cyber threats, which is clearly not sufficient to protect human brain and psyche against the 'hacking.'(Ueoka, 2018) One example of this was when a team of cyber security experts had effortlessly hacked a popular app designed for business and personal meetings in VR where they were able to add themselves into any room (even private ones), to view users' screens in real-time, and to

\footnotetext{
3 General Forecast for VR/AR: What Industries Gan Gain Profits Using These Technologies by 2025 (in Russian) https://www.cossa.ru/trends/232319/

4 See an official website of a Teslasuit developer https://teslasuit.io/

5 Teslasuit: a Suit that Changes Reality https://ichip.ru/teslasuit-kostyum-kotoryjj-menyaet-realnost.html

6 Xinmei Shen. Drug rehabilitation centers in China are using VR to treat addicts. https://www.abacusnews.com/digital-life/drug-rehabilitation-centers-china-are-using-vr-treat-addicts/article/2152517.
} 
send them malware apps among other things. ${ }^{7}$

Therefore, VR is an effective way of projecting influence on human consciousness and subconsciousness, which can become available to hackers, cyber forces of foreign governments, and both software and hardware producers.

These vulnerabilities can become a weapon of cyber warfare between the states (by ways of projecting mental effects on the users of a certain country), or even a tool for acquiring a confidential information. ${ }^{8}$ While what was available to cyber criminals before was only personal possessions, business reputation, and other obvious valuable assets, now they can literally get into the brain of their victims. VR offers opportunities for an effective manipulation with consciousness and emotions, which are only limited to their developer's imagination. Most recent studies show that virtual reality can help induce virtually any emotion that can last up to 8 minutes of a time (Meuleman, 2018).

\subsection{Insufficiency of Knowledge about the Impact It Has on Humans}

The fourth feature of VR is insufficiency of knowledge about the impact it has on humans. As of now, there are few research projects on this topic that are actively developing and that already have available research findings, which demonstrate both negative and positive effects of VR in specific contexts. At the same time, these findings show that virtual reality has effects only for specific applications in specific fictional environment in specific conditions from a short-term perspective.

For instance, there is no research on the impact that a frequent use of VR has on a mental state of children, adolescents, or adults. As a result, development of the rules of regulation of virtual reality for specific age groups now can be only be done based on the assumptions by analogy.

Even if such a research projects were done, technologies in this industry develop so rapidly that their findings would become instantly outdated. Let's assume that a certain piece of VR hardware or software is proven to be secure in the long run. Most probably within a year ${ }^{9}$ there would be a release of a new model with a higher degree of realism and immersion into a virtual reality, and that would make the research findings irrelevant. Thus, the reasoning of the development of a system of legal regulation would become a series of outdated, controversial, and non-generalizable research findings.

This is a serious problem as any legal regulation should have its reasoning. VR is not a piece of equipment that requires clinical testing and security issues studies, which is why it becomes virtually impossible to force developers conduct a research on the negative effects that this technology might have on the users.

From this perspective, virtual reality can be classified as a highly realistic imitation of both real and fictional worlds, which offers a high degree of immersion and a low degree of protection against cyber-attacks. This technology is still poorly studied, especially in the context of negative consequences for both physical and mental health of users in the long run.

\section{Findings and Discussion}

Features of VR as a technology listed above may lead to certain effects related to the legal regulation.

First, the legal approach of regulation of this sphere is not exactly clear. On the one hand, VR is one of the human-computer interfaces similar to video games or traditional office applications; on the other hand, it has a strong psycho-physical effect that is not typical for traditional interactive computer interfaces.

With a simple transposition or application of regulations used in the computer industry, such as those applied in the video games, there still remain multiple unregulated issues that impose risks on the users.

Video games are usually labeled for specific age categories, primarily based on the content and the design of the game (Zamakhina, 2019). Largely the labeling system of the gaming content has already been established, however, it will not fit the VR apps as it does not evaluate potential harm and an accumulating long-term impact.

At the same time, legal norms used to regulate relations that emerge in the real physical world, are also not applicable in VR. For instance, homicide that has occurred in the virtual world, if not accompanied by a death of a victim in the real world, in the foreseeable future will not become a felony like a traditional homicide is. This argument however has its exemptions.

\footnotetext{
${ }^{7}$ Hacking Virtual Reality - Researchers Exploit Popular Bigscreen VR App. https://thehackernews.com/2019/02/bigscreen-vr-hacking.html Entry of Cyber Warfare http://www.tadviser.ru/index.php/\%D0\%A1\%D1\%82\%D0\%B0\%D1\%82\%D1\%8C\%D1\%8F:\%D0\%9A\%D0\%B8\%D0\%B1\%D0\%B5\%D1 $\% 80 \% \mathrm{D} 0 \% \mathrm{~B} 2 \% \mathrm{D} 0 \% \mathrm{BE} \% \mathrm{D} 0 \% \mathrm{~B} 9 \% \mathrm{D} 0 \% \mathrm{BD} \% \mathrm{D} 1 \% 8 \mathrm{~B}$

${ }^{9}$ That is the average time of a release of new hardware, software gets updated much more frequently.
} 
For instance, some scholars point out to the fact that substitution of a sex partner or gaining an illegal access to the body of the virtual reality user through the interface (an electronic sex toy) for intimate connection contains elements typical for offences against sexual freedom of a person. In legal research publications, such felonious act is either perceived as a sexual harassment or as a rape (Strikwerda, 2015).

With some exceptions, most scholars would agree that actions in the virtual world even with its increasing realism so far do not impose the same effects on the users as do the actions in the real world (Alptraum, 2015). Thus, direct transposition of the legal norms applied in other IT industries does not work in VR as it remains to be an imitated world, which is why norms applied to regulate relations in the physical world are not applicable there.

Second, VR offers ways of social interaction that have not been known before. These are social relations that have properties of both the real world and the cyberspace. Just like relations between the users in the cyberspace, interactions in the virtual reality have a global dimension (or a transboundary character) as while being anonymous for their participants, they have a wide scope of the audience and other typical features (Dremliuga, 2008). At the same time, these relations have one distinguishing element, which is a strong psychophysical effect imposed on the users comparable to their reactions in the real world.

For instance, how would we essentially classify physical intimacy that people might have with assistance of VR with a physical feedback? Would it be classified as a video content distribution via internet as the images and the sounds are transmitted into the VR helmet, or would it be classified as actions of sexual nature as there is an interaction between the persons' genitals?

Even if the use of VR does not imply an active interaction with the human body, it still can be difficult to identify the nature of relations by means of this technology. This is illustrated by the fact that virtual reality technologies also actively develop in an academic setting.

Application of VR technologies in teaching allows finding more effective ways to introduce students to a complex scholarly information, which helps with the improvement of both the quality and efficiency of teaching (Vishwanath, 2017; Monaenkova, 2017). At the same time, it remains unclear how teaching in VR would be regulated. Would this teaching be limited to specific age groups as there exists a proven evidence of certain psychophysical effects on people of different ages? (Heidrich, 2019) Would teaching in VR enjoy the same status as the relations between teaching institutions and their students?

Due to their exposure to the virtual world, oftentimes users might experience physical space disorientation and inability of properly coordinate their actions in the real world, which can cause physical harm not only to the users themselves but also to others around them and to their property (Ramirez, 2019). Should these relations be regulated just like the teaching process in the teaching institutions?

Besides, possible deliberate negative mental effects imposed on others should also be considered. Imagine, cybercriminals hack a VR app. With the use of different techniques (infralow or ultrahigh acoustic waves frequencies, particular combination of colors with a required flicker frequency, hypnosis, etc.) one could impose desired mental effects on the users, which among other things might cause serious mental disturbances among them. This should be considered when it comes to such easily psychologically disturbed groups of users as high-school and college students. Would this kind of actions be classified as actions causing a harm similar to the actions causing a harm is the real world, or would they be regulated by the laws on the distribution of information?

Third, VR being an information technology inherits the challenges typical for the regulation of a cyberspace. One of the major challenges here is that cyberspace belongs to multiple jurisdictions. Some researchers mention it as a Bangladesh Problem (Lemley, 2018). The idea behind it is that application of any law has a limited geographic reach (Dremliuga, 2019). For instance, if an unlawful act is committed against a person in virtual reality, it might turn out that the lawbreaker could avoid taking responsibility as unlawful act was committed from the territory of Bangladesh if in accordance with the local laws this act would not be considered to be a lawbreaking or if there would be no mechanism of holding lawbreakers from abroad liable for their offences.

Moreover, in the opinion of some researchers impunity might become a reason of increasing numbers of unlawful transboundary acts in VR (Lemley, 2018), which in its turn, for instance, might cause increasing numbers of other types of cybercrime (Dremliuga, 2008). In other words, in VR offenders might get a desired effect caused by the offence as they would in the real world being exposed to a lesser jeopardy.

Information technologies make many unlawful things more economically efficient. For instance, if criminal offenders wish to hide themselves from prosecution in the real world, they would need to spend significant 
resources to ensure their mobility and to conceal their identity under a permanent fear of being unmasked by a potential victim. Cyberspace lowers these costs and gives offenders an opportunity of being far away from the victim. Here VR adds realism to cyber interaction, which enhances its efficacy.

From the conceptual perspective, challenges of legal regulation of cyberspace are not something new however sustainable solutions still remain unavailable. This is illustrated by a situation when attempts to control internet have led to the development of tools that help skirt around this control. The most visible examples here are Tor Browser and Telegram Messenger - while the former one allows an access to Darknet websites, ${ }^{10}$ the latter one still remains fully operational regardless of the RosComNadzor attempts to block it. ${ }^{11}$ Thus, VR as a unique digital technology inherits many features that make regulation of relations in the cyberspace more difficult.

\section{Conclusions}

This article does not aim to give exhaustive answers to the questions that apply to the regulation of VR. Rather the author of the article attempts to outline the framework of further research and to list major factors that have their impact on the law-making in this sphere. Virtual reality is a technology that imitates reality with a high degree of realism and immersion. Both software and hardware solutions have a low level of cybersecurity not comparable to a potential damage that they may cause. Due to these unique features, a general approach towards regulation of VR-based relations still remains ambiguous. Besides, this technology inherits most of issues associated with the formation of an effective system of regulation of a cyberspace. Contemporary research findings in the field of a secure application of VR is academic training and entertainment get rapidly outdated due to their inability to catch up with the development of technologies.

\section{Acknowledgments}

The study was performed with the financial support of the Endowment Fund of the Federal State Autonomous Educational Institution of Higher Education "Far Eastern Federal University" as part of the research project No. 18-08-0022.

\section{References}

Abdullah, M., \& Shaikh, Z. A. (2018). An effective virtual reality-based Remedy for acrophobia. International Journal of Advanced Computer Science and Applications, 9(6), 162-167. https://doi.org/10.14569/IJACSA.2018.090623

Ahn, S. J. G., Bostick, J., Ogle, E., Nowak, K. L., McGillicuddy, K. T., \& Bailenson, J. N. (2016). Experiencing Nature: Embodying Animals in Immersive Virtual Environments Increases Inclusion of Nature in Self and Involvement with Nature. Journal of Computer-Mediated Communication, 21(6), 399-419. https://doi.org/10.1111/jcc4.12173

Alptraum, L. (2015). Cam Girls Are Charging Clients to Control Their Vibrators Over the Internet. Tech by Vice. Retrieved from https://motherboard.vice.com/en_us/article/ae35be/cam-girls-are-hacking-teledildonics-to-make-virtual-sex -feel-real

Bansal, A., Weech, S., \& Barnett-Cowan, M. (2019). Movement-Contingent Time Flow in Virtual Reality Causes Temporal Recalibration. Scientific Reports, 9(1), 43-78. https://doi.org/10.1038/s41598-019-40870-6.

Brungart, D. S., Kruger, S. E., Kwiatkowski, T., Heil, T., \& Cohen, J. (2019). The Effect of Walking on Auditory Localization, Visual Discrimination, and Aurally Aided Visual Search. Human Factors, 61(6), 976-991. https://doi.org/10.1177/0018720819831092

Clark, L. (2013). Walking the Plank with the Oculus Rift is Stomach-Churning Stuff. WIRED UK, (May 30, 2013). Retrieved from http://www.wired.co.uk/article/oculus-vr

Diemer, J., Alpers, G. W., Peperkorn, H. M., Shiban, Y., \& Mühlberger, A. (2015). The impact of perception and presence on emotional reactions: A review of research in virtual reality. Frontiers in Psychology, 6 (JAN), art. no. 26. https://doi.org/10.3389/fpsyg.2015.00026

Dremliuga, R. (2008). Internet Crime. Far Eastern National University Press.

Dremliuga, R. (2019) Crimes in Virtual Reality. Revista Dilemas Contemporáneos: Educación, Política y Valores, 7(1). 1-14. Retrieved from

\footnotetext{
${ }^{10}$ Darknet due to its architecture remains very difficult to get blocked

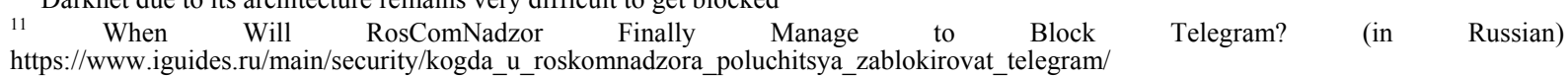


General Forecast for VR/AR: What Industries Gan Gain Profits Using These Technologies by 2025. COSSA (in Russian) Retrieved from https://www.cossa.ru/trends/232319/

Global virtual reality video gaming sales revenue 2015-2020. Retrieved from https://www.statista.com/statistics/499714/global-virtual-reality-gaming-sales-revenue/

Heidrich, D., Oberdorfer, S., (2019). Latoschik, M. E. The effects of immersion on harm-inducing factors in virtual slot machines. 26th IEEE Conference on Virtual Reality and 3D User Interfaces, VR 2019 Proceedings, 8798021, 2019P. 793-801.

https://dilemascontemporaneoseducacionpoliticayvalores.com/_files/200006019-371bb371bc/19.09.129\%20

Delitos\%20en\%20realidad\%20virtual.pdf

Hvass, J., Larsen, O., \& Vendelbo K. (2018). Visual realism and presence in a virtual reality game. 3DTV-Conference 2017-Jun, 1-4. https://doi.org/10.1109/3DTV.2017.8280421

Lemley, M. A., \& Volokh, E. (2018). Law, virtual reality, and augmented reality. University of Pennsylvania Law Review, 166(5), 1071-1172. http://dx.doi.org/10.2139/ssrn.2933867

Meuleman, B., \& Rudrauf, D. (2018) Induction and profiling of strong multi-componential emotions in virtual reality. Proceedings of IEEE Transactions on Affective Computing, 2018. Retrieved from https://ieeexplore.ieee.org/document/8432120/

Monaenkova, E. B. (2017) Impact of Virtual Reality on the Mental Health of the University Students. Development of Contemporary Research: Theoretical and Applied Aspects, 12, 41-54.

Park, J.-M., \& Noh, G.-Y. (2018). The effects of VR simulation game on driving fear and efficacy. JP Journal of Heat and Mass Transfer, 15(Special Issue 2), 161-169. https://doi.org/10.17654/HMSI218161

Published by the Internet Initiatives Development Fund. (2017). Market of Virtual and Augmented Reality: Opportunities for Start-up Companies from the Perspective of an Investor. Retrieved from https://habr.com/ru/company/friifond/blog/322230/

Ramirez, E. J. (2019). Ecological and ethical issues in virtual reality research: A call for increased scrutiny. Philosophical Psychology, 32(2), 211-233.

Strikwerda, L. (2015). Present and Future Instances of Virtual Rape in Light of Three Categories of Legal Philosophical Theories on Rape. Philosophy and Technology, 28(4), 491-510. https://doi.org/10.1007/s13347-014-0167-6

Tardif, N., Therrien, C.-E., \& Bouchard, S. (2019). Re-Examining Psychological Mechanisms Underlying Virtual Reality-Based Exposure for Spider Phobia. Cyberpsychology, Behavior, and Social Networking, 22(1), 39-45. https://doi.org/10.1089/cyber.2017.0711

Thaler, A., Creem-Regehr, S. H., \& Pujades, S. (2019). The influence of visual perspective on body size estimation in immersive virtual reality. Proceedings -SAP 2019: ACM Conference on Applied Perception, 2019, a5. https://doi.org/10.1145/3343036.3343134

Ueoka, R., \& AlMutawa, A. (2018). Emotion hacking VR: Amplifying scary VR experience by accelerating actual heart rate. Lecture Notes in Computer Science (including subseries Lecture Notes in Artificial Intelligence and Lecture Notes in Bioinformatics), 10904 LNCS, 436-445. https://doi.org/10.1007/978-3-319-92043-6_37

Vishwanath, A., Kam, M., \& Kumar, N. (2017). Examining low-cost virtual reality for learning in low-resource environments in Proceedings of the 2017 Conference on Designing Interactive Systems (Edinburgh: ACM). 1277-1281. https://doi.org/10.1145/3064663.3064696

Xinmei, S. (n.d.). Drug rehabilitation centers in China are using VR to treat addicts. Retrieved from https://www.abacusnews.com/digital-life/drug-rehabilitation-centers-china-are-using-vr-treat-addicts/article/ 2152517

Yuan, S. N. V., \& Ip, H. H. S. (2019). Using virtual reality to train emotional and social skills in children with autism spectrum disorder. London Journal of Primary Care, 10(4), 110-112. https://doi.org/10.1080/17571472.2018.1483000

Zamakhina, T. (2019). My Parents are Gadgets. Video Games Available Online Will Get Their Age Markers. Russian Gazette. Moscow Edition, 106(7864). Retrieved from https://rg.ru/2019/05/19/kompiuternye-igry-razmeshchennye-v-seti-poluchat-vozrastnye-markery.html 


\section{Copyrights}

Copyright for this article is retained by the author(s), with first publication rights granted to the journal.

This is an open-access article distributed under the terms and conditions of the Creative Commons Attribution license (http://creativecommons.org/licenses/by/4.0/). 